\title{
Safety of patients with mental disorders: a collective construction of strategies
}

\author{
Segurança do paciente com transtorno mental: construção coletiva de estratégias \\ Seguridad del paciente con trastornos mentales: construcción colectiva de estrategias
}

Fernanda Cordeiro Sirtoli Vantil'
ORCID: 0000-0002-3601-3394

Eliane de Fátima Almeida Lima'

ORCID: 0000-0001-5128-3715

Karla Crozeta Figueiredo" ORCID: 0000-0003-3544-5643

Leila Massaroni' ORCID: 0000-0001-7327-887X

Ana Inês Sousa"' ORCID: 0000-0002-0214-0723

Cândida Caniçali Primo' ORCID: 0000-0001-5141-2898

'Universidade Federal do Espírito Santo. Vitória, Espírito Santo, Brazil. " Universidade Federal do Paraná. Curitiba, Paraná, Brazil. I"Universidade Federal do Rio de Janeiro. Rio de Janeiro, Rio de Janeiro, Brazil.

How to cite this article: Vantil FCS, Lima EFA, Figueiredo KC, Massaroni L, Sousa Al, Primo CC. Safety of patients with mental disorders: a collective construction of strategies. Rev Bras Enferm. 2020;73(1):e20170905. doi: http://dx.doi.org/10.1590/0034-7167-2017-0905

\section{Corresponding Author:}

Eliane de Fátima Almeida Lima

E-mail: elianelima66@gmail.com

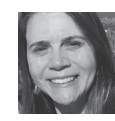

EDITOR IN CHIEF: Dulce Aparecida Barbosa ASSOCIATE EDITOR: Hugo Fernandes

\section{ABSTRACT}

Objective: to describe risk management implementation in the safety of patients with mental disorders through action research. Method: an action research carried out with a multidisciplinary team from a reference hospital in mental health in Southeast Brazil. Results: three strategies considered as managerial technologies for the mentally ill patient were developed: risk management diagram for patient safety; patient safety protocols; and textual proposal of software for internal management of incident notifications. Final considerations: this action research allowed a collective discussion by the whole multidisciplinary team, enabling strategy drafting for risk management implementation and improvement of care quality in the safety of patients with mental disorders at the study site.

Descriptors: Patient Safety; Mental Disorders; Risk Management; Technology; Mental Health Care.

\section{RESUMO}

Objetivo: descrever a implantação da gestão de risco para a segurança do paciente com transtorno mental por meio da pesquisa-ação. Método: pesquisa-ação realizada com equipe multidisciplinar de um hospital referência em Saúde Mental na região Sudeste do Brasil. Resultados: foram elaboradas três estratégias consideradas tecnologias gerenciais para o paciente com transtorno mental: diagrama da gestão de risco na segurança do paciente; protocolos de segurança do paciente; e proposta textual de software para gestão interna de notificações de incidentes. Considerações finais: a pesquisa-ação permitiu uma discussão coletiva por toda a equipe multiprofissional, possibilitando a elaboração de estratégias para a implantação da gestão de risco e a melhoria da qualidade da assistência na segurança do paciente com transtorno mental no local do estudo.

Descritores: Segurança do Paciente; Transtornos Mentais; Gestão de Riscos; Tecnologia; Assistência à Saúde Mental.

\section{RESUMEN}

Objetivo: describir la implementación de la gestión de riesgos en la seguridad de los pacientes con trastornos mentales a través de la investigación de acción. Método: investigación de acción realizada con un equipo multidisciplinario de un hospital de referencia en salud mental en el sureste de Brasil. Resultados: se desarrollaron tres estrategias consideradas como tecnologías de gestión para el paciente mentalmente enfermo: diagrama de gestión de riesgos para la seguridad del paciente; protocolos de seguridad del paciente; y propuesta textual de software para la gestión interna de notificaciones de incidencias. Consideraciones finales: la investigación de acción permitió una discusión colectiva por parte de todo el equipo multiprofesional, lo que permitió la elaboración de estrategias para la implementación de la gestión de riesgos y la mejora de la calidad de la atención en la seguridad de los pacientes con trastornos mentales en el lugar de estudio.

Descriptores: Seguridad del Paciente; Trastornos Mentales; Gestión de Riesgos, Tecnología; Atención a la Salud Mental. 


\section{INTRODUCTION}

The World Health Organization in 2004 presented guidelines, through the Global Alliance for Patient Safety and Global Challenges, on actions that help to avoid risk to the patient and guidelines for implementing safe care measures ${ }^{(1)}$.

In Brazil, the World Health Organization works with the Brazilian National Health Surveillance Agency (ANVISA - Agência Nacional de Vigilância Sanitária). As established in MoH/ANVISA Resolution Collegiate Board of Directors (RDC - Resolução da Diretoria Colegiada) number 63 of November 25, 2011, the Health Service must create mechanisms and strategies that allow structuring a quality policy, in addition to defining that quality assurance be used as management technology ${ }^{(2)}$.

Ordinance 529 of April ${ }^{\text {st }} 2013$, instituted the Brazilian National Patient Safety Program (Programa Nacional de Segurança do Paciente), whose general objective was to contribute to the qualification of health care in all health facilities in the national territory ${ }^{(3)}$. In addition, it became mandatory to set up a Patient Safety Center, through RDC number 36 of July 25, 2013 of MoH/ANVISA, which instituted actions for patient safety in health services ${ }^{(4)}$.

In patient safety, risk management aims at the early identification of potential risks and, consequently, decrease or elimination of adverse effects resulting from health care. It also states that there must be guarantees by the risk manager to prevent, detect, record and correct deficiencies, and it is necessary to insert strategies for the change in the failure detection culture ${ }^{(5)}$.

When it relates to quality, risk management and patient safety, emphasis is placed on the effectiveness of monitoring activities (aiming to detect problems and control the maintenance of improvements achieved by the actions already implemented); cycle of improvements (expansion and development of proposals to solve security problems); and quality planning and art or design (processes and flows for management implementation) ${ }^{(3)}$.

In mental health care, differential management is necessary, given that the public served has a profile that may predispose to the occurrence of some events, and may even be harmful to the patient, such as self-harm, violence and suicide. Thus, it is a fact that the discussion about the safety of patients with mental disorder is something that should be discussed and studied(6).

Implementing measures to improve patient safety is essential, particularly in a psychiatric hospital. Studies point to some limitations in the physical structure, in the quantitative of health professionals and in the organization of services that can generate risks to patient, employee and visitor safety ${ }^{(7-8)}$. From this perspective, it is questioned: what strategies can be developed in risk management to improve the safety of patients with mental disorders?

\section{OBJECTIVE}

To describe risk management implementation in the safety of patients with mental disorders through action research.

\section{METHOD}

\section{Ethical aspects}

The present work respected the ethical principles regarding research with human beings. It was appreciated and approved by the Research Ethics Committee of Universidade Federal do Espirito Santo's Science and Health Center on July $13^{\text {th }} 2016$. All participants voluntarily signed the Free and Informed Consent Term.

\section{Theoretical-methodological framework and type of study}

This is a qualitative approach action research study(9), which followed the criteria of COREQ checklist (COnsolidated criteria for REporting Qualitative research), in the research organization.

\section{Methodological procedures}

\section{Study setting}

The study was developed in a hospital of clinical attention reference in mental health, in a municipality of the Southeast of Brazil. The study hospital has 113 beds, of which 74 are for mental health care and 39 are intended for clinical care. The hospital has 183 health professionals ( 25 nurses, 21 psychiatrists, 21 clinical physicians, 02 pharmacists, 03 physiotherapists, 01 speech therapists, 114 nursing technicians/assistants, 05 psychologists, 03 occupational therapists, 07 social workers, 02 nutritionists). Besides these, there is also a team with 15 professionals of multidisciplinary reference for the organization of daily care to patients with mental disorder.

\section{Data source}

Participants were the multidisciplinary reference team members responsible for care for patients with mental disorders (nurses, physicians, speech therapists, social workers, occupational therapists, psychologists and pharmacists). Currently, this team is composed of 15 members invited to participate in the study by means of an invitation letter, filling in an identification of participants' profile and signing the Free and Informed Consent Term. It was established as inclusion criteria to be a multidisciplinary reference team member. For exclusion criteria, it was adopted to be away from the service due to leave or vacations and did not participate in two or more meetings. Therefore, 13 people participated, due to a leave due to maternity leave and another due to vacations.

\section{Collection and organization of data}

The data collection took place in the period from October 3, 2016 to March 27, 2017. Action research is developed in twelve phases, which are flexible, not necessarily following a rigid order, and may in some cases be developed in one moment. The phases are: I. Exploratory phase; II. Research theme; III. Problem placement; IV. Theory place; V. Hypotheses; SAW. Seminars; VII. Observation field, sampling and qualitative representativeness; VIII. Data collection; IX. Learning; X. Informal/formal knowledge; $\mathrm{XI}$. Action plan; XII. External disclosure ${ }^{(9)}$. In Figure 1, there is a scheme about research development. 


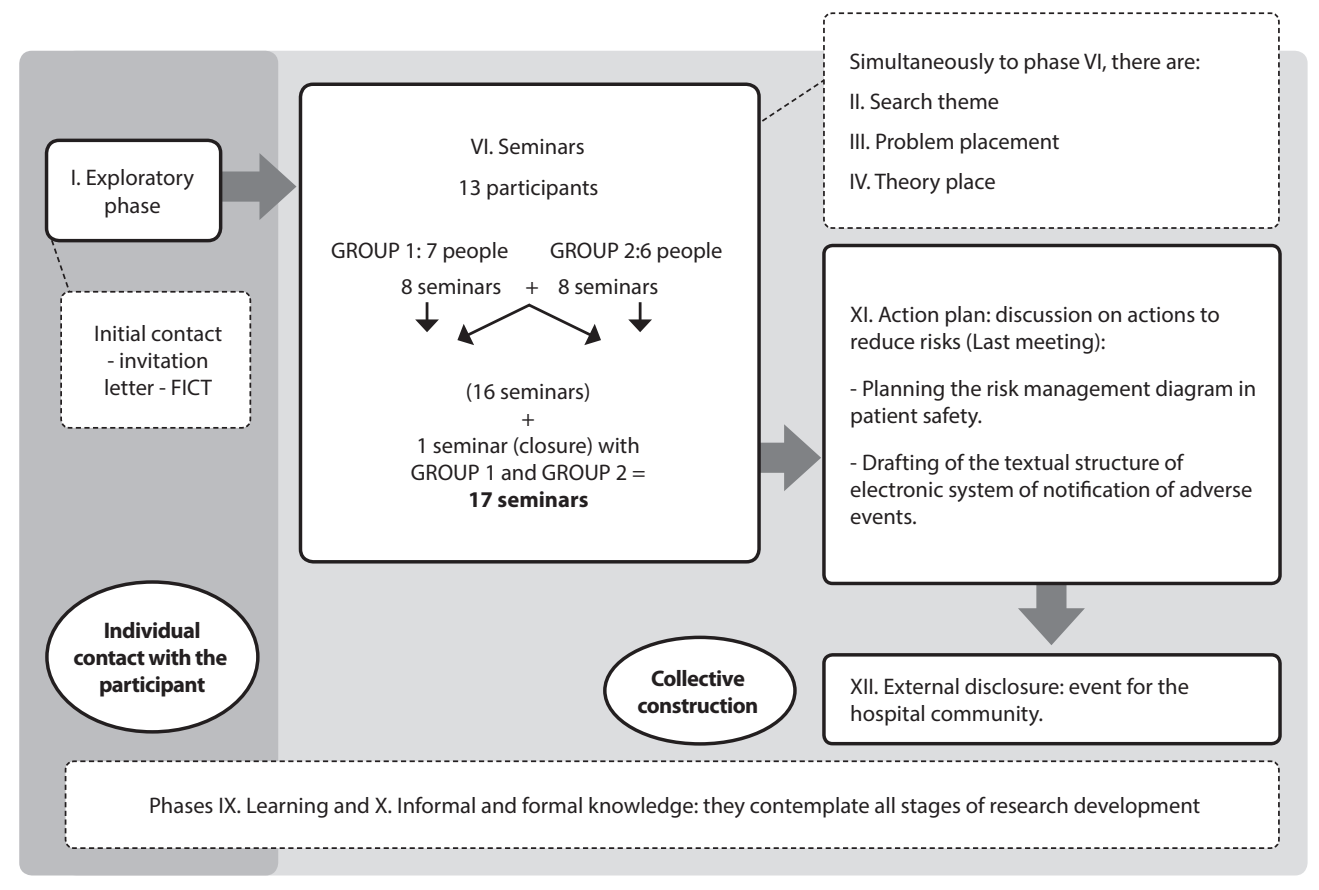

Figure 1 - Description of the action research's phases, Vitória, Espírito Santo, Brazil, 2017
4. Prescription and Safe Administration of Medications; 5. Patient Evasion Prevention; 6. Preventing Restraint Injury; and 7. Fall Prevention. At the last meeting, the $17^{\text {th }}$ seminar, all protocols duly formatted and validated by agreement were presented by the group. In this seminar, the risk management tree diagram in the safety of patients with mental disorders and the textual proposal of software for internal management of incident reports, both developed through content analysis of group discussions, were exposed and assessed by participants.

The tool used consisted of logbook or field diary. In addition, all seminars were recorded in MP3 by $\mathrm{R}-704 \mathrm{~GB}$
Participants were divided into two groups, nominated 1 and 2 . Each group participated in 8 meetings, in addition to the closing meeting, which was held in a single event with both groups. In the 16 seminars, priority identification and the risk factors that involved the safety of patients with mental disorders was carried out. Soon after, protocol structure was defined (what would be document components). Protocols were then drawn up. After each meeting, the content discussed was analyzed and formatted within the protocol standard defined by the group and delivered to participants for assessment and validation by agreement. At the next meeting they were collected with the appropriate suggestions. Furthermore, 7 protocols were developed: 1. Patient Correct Identification; 2. Hand Hygiene; 3. Violence Prevention;
MP3 digital voice recorder, transcribed in full in record minutes and authorized by participants, which was stated at each beginning of the events held.

\section{Data analysis}

For data analysis, systematized content analysis, applied in the scope of action research ${ }^{(10)}$. Figure 2 shows the description of data analysis process.

A code (P1, P2 ...) was established to preserve anonymity, and symbols were used, such as [...] meaning that part of speech was omitted.

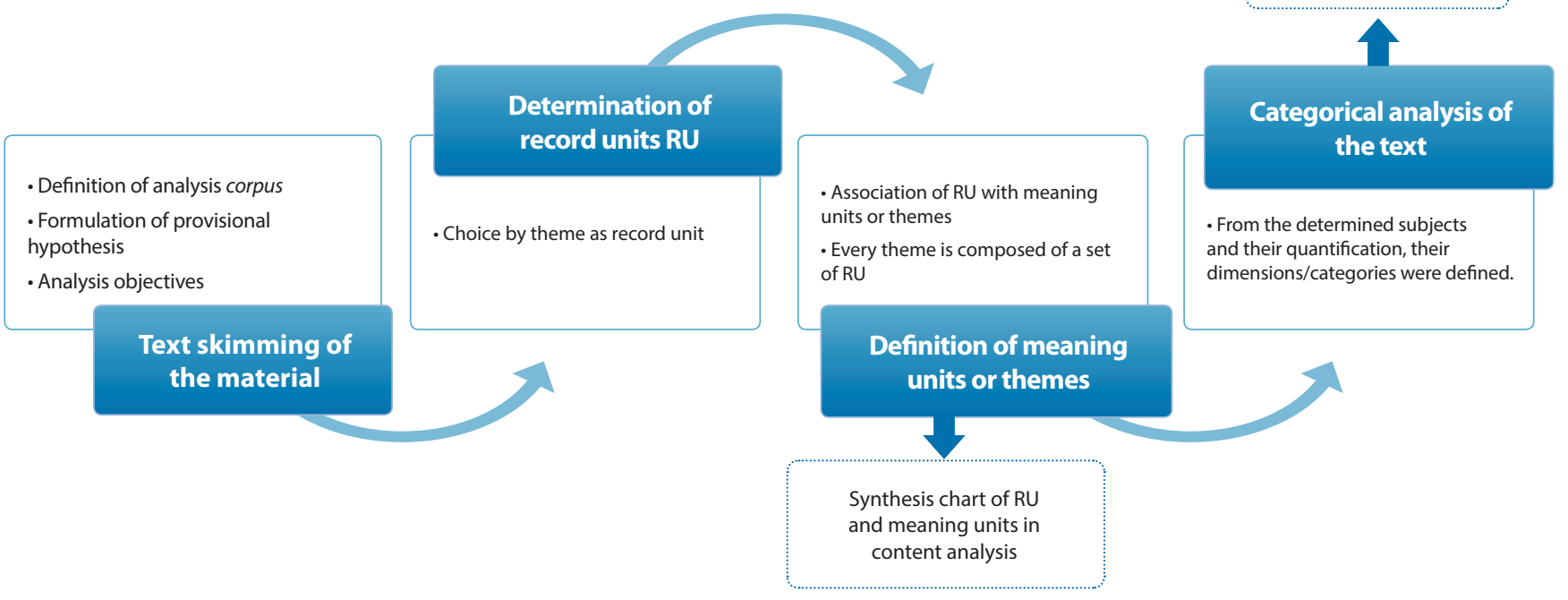

Figure 2 - Description of the data analysis process, Vitória, Espírito Santo, Brazil, 2017 


\section{RESULTS}

Thirteen participants from the multidisciplinary team, with a mean age of 32.9 years, participated in the study. Among these, 11 were female and 02 were male. As to maximum professional degree, one participant held master's degree, while the others held specialization. About mental health work, 8 participants have 1 to 5 years of experience, the other 5 participants have 6 to 10 years of mental health. The group was composed of 05 nurses, 02 social workers, 03 psychologists, 01 speech therapist, 01 pharmacist and 01 physician.

From the analysis of seminars' textual corpus, 03 categories emerged: "Action research as a collective strategy for the organization of risk management in the safety of patients with mental disorders", "Protocol construction", and "Drafting of diagram and textual proposal of software for internal management of incident reports" below.

\section{Action research as a collective strategy for the organiza- tion of risk management in the safety of patients with mental disorders}

Regarding participants' perception regarding research, knowledge collective production, team valorization, opportunity to participate in a research, management tools production for patient safety stand out. With the development of this research, the Patient Safety Center was implanted in the institution, and protocols and decision tree elaborated were presented to all clinical and reference staff, being implemented in the institution.

[...] for patient safety, it was a breakthrough. Now, we already have protocols ready, and management has already requested composition and Patient Safety Center implementation. There was awareness of the team for a theme so current and so important. (P8)

[...] the fact that we have, as a team, a place to express ideas, to listen to the other people involved in the assistance and to create, in a collective way, tools to work better, to guarantee quality of services, it is very gratifying. Another important point is that we, from our work directly with patients, completely technical, we return to participate in the middle of the research, which is important to arouse interest in studying and research. (P11)

[...] I knew and read a lot about it. And now I'm from the Patient Safety Center, and what's written here will be great. This research was at the right time. And the choice of this way, of joining professionals, discussing, assessing, then revalidating with everyone was very cool. (P2)

\section{Protocol construction}

In this category, participants discussed the specificity of mental health, since they are patients with specific characteristics and need to elaborate protocols that highlight these particularities. Next, it was pointed out which protocols were priorities for patients with mental disorder and which organizational structure would be used for protocol construction.

Participants mentioned the protocols that are recommended by ANVISA, but emphasized that, for mental health, there is a need for adequacy.
[...] protocols that are already established by ANVISA, or can we think of others? Psychiatry is very atypical. (P1)

[...] the profile of our patients is not to make a pressure ulcer. They walk, they move. The problem is when it has to contain. (P3)

According to participants' reports, the priorities for the elaboration of protocols defined by the whole group were: Patient Evasion Prevention; Patient Correct Identification; Fall Prevention; Injury Prevention due Mechanical Restraint; Hand Hygiene; Prescription and Safe Administration of Medications; and Violence Prevention.

[...] I think aggression should also be talked about. Among the patients themselves, physical, sexual. Verbal, nor do we consider. (P6)

[...] my opinion is that, based on this material that has the minimum protocols, which are established by ANVISA, in fact we have to go by exclusion, since they are established. We simply have to do it all. I say, do everything that fits our reality, we cannot just do not do. Priorities would be hand hygiene, prescription and safe administration, falls, patient identification. Safe surgery does not go in because we do not do surgery and pressure ulcer prevention, which I believe is not the profile of our patients developing this type of injury, other than those who develop a contention injury, who might perhaps do something about it. (P10)

The group proposed an organizational structure of protocols that contained as a sequence: definition, protocol purpose, protocol coverage, risk factors, prevention measures, how to proceed in situations, notification, indicators and references.

[...] one must follow a logic, for example fall protocol, I believe that has to have concept of fall; second topic: practices to reduce the occurrence of falls; risk factors for falls, how to proceed, etc. This must all be within the protocol. (P13)

[...] patient safety protocols must be monitored, we must have indicators that are followed up, so we have the parameter of how the institution is and the adverse events for each protocol. In order to have indicators, we need to define what is going to be notified, we need the notification made by health professionals or even family members about what happens. Therefore, they have to be in protocol, indicators and notification. (P5)

Then, the group discussed, based on the organizational structure's sequence, each protocol theme. In this sense, the protocol construction category was subdivided into 7 subcategories: Patient Evasion Prevention; Patient Correct Identification; Fall Prevention; Injury Prevention due Mechanical Restraint; Hand Hygiene; Prescription and Safe Administration of Medications; and Violence Prevention.

In the Evasion Prevention subcategory, participants reported concern and the need for a standardization of how to act in these occurrences, due to aspects of the psychiatric.

[...] mental disorder must be handled in case of evasion, because the patient may suffer a run over, or do some act of aggression. We need to know how to conduct this. (P2)

Regarding protocol purpose, the group decided that it will be to ensure continuity of patient care in the hospitalization unit; 
ensure the patient's physical and mental integrity; and avoid damages arising from the circumvention of an individual with limited decision-making.

[...] the hospital must guarantee continuity of care in the hospitalization sector. (P1)

[...] in addition to that patient physical and mental integrity has to be also guaranteed. (P9)

In the Patient Correct Identification subcategory, participants reported concern about the severity of risks of misidentification in patients with mental disorders:

[...] sometimes the patient himself changes bed, and still ask himself, speak the name of the other. (P4)

[...] everything must be notified. Both the occurrence of incorrect identification with damage, and the occurrence of incorrect identification without damage, to the situations in which the patient is without identification. This is very serious because psychotropic medications are very complex. (P6)

In the Fall Prevention subcategory, there was agreement of the group regarding risk factors. Professionals reported factors related to the environment and the profile of patients:

[...] risk factor would be: medicines that cause a lot of drowsiness, loss of body balance, postural hypotension, urinating and slipping, stairs in the yard. (P08)

[...] another risk factor: burnt out light bulbs. At night this is a great risk. Another risk: cleaning staff wash corridors with patients in the wards. As a protective measure, you should maintain your lights and roof, and organize and plan cleaning at times when you have the least patient transiting. The ideal would be to eliminate the ladder. (P12)

Regarding purpose, the group pointed out that in addition to correcting the risks, there is a need for awareness of the hospital community:

[...] the purpose would be to reduce the occurrence of fall of patients in the assistance points and patios, as well as to raise awareness about multidisciplinary care to promote a safe environment. (P10)

Participants reported in the Injury Prevention due Mechanical Restraint subcategory, a concern regarding legality of mechanical restraint procedure.

[...] first, I think we have to look for the legislation that refers to restraint, especially of professional councils, and make clear the performance and legality of this for each professional. (P12)

The concern of professionals about the damages that this practice causes in patients, when performed incorrectly, was perceived:

[...] many times we receive the patient, the restraint is made and by wrong and wrong technique, the patient has to be transferred to the clinical ward. Sometimes his case would be dealt with in a day or two, and because of that, he stays here for about seven days. (P9)

As protocol purpose, it was defined to avoid the occurrence of mechanical restraint injury in patients who need this procedure; to make professionals aware of the damage that can be caused by an incorrect mechanical restraint technique; to guide health professionals about the use indication of mechanical restraint; to instigate professionals to rethink their purpose, indication and ways of using it, so that it is a therapeutic procedure and not of repression.

[...] that one of the main objectives is to make professionals aware. What I see sometimes is that this is done as punishment repression. (P4)

[...] we have to educate professionals. I do not think they have any idea of the harm they cause. (P5)

In addition, the report was also about the lack of adequate materials to perform the technique:

[...] but some are unaware of the correct technique. And often, it does not have the restraint within what is recommended, and the staff is held hostage by improvisation. (P5)

In the Hand Hygiene subcategory, participants discussed handwashing culture and, as a result, the lack of awareness about process importance was highlighted as one of the main risk factors:

[...] lack of awareness about the importance of hand hygiene, as well as complications that may occur in the patient, such as infections. (P5)

When discussing the notification, it was concluded that the lack of condition for Hand Hygiene is one of the events that should be reported:

[...] notification should occur when there is any difficulty sanitizing hands. A faulty faucet, lack of paper towel, or soap, etc. (P6)

In the Prescription and Safe Administration of Medications subcategory, the discussion was extensive. The group was very concerned about medication-related errors and reported that patients have certain characteristics that may leave them vulnerable to damage:

[...] patient's state of consciousness; patients in nearby beds within the same ward with the same or similar names; wrong prescriptions. (P4)

Other risk factors related to the institution were mentioned:

[...] very similar medicines in bottles very similar, professional deficit; professional unpreparedness, professional deficit; professional unpreparedness. (P2)

Regarding medical prescription, it was agreed by the whole group that this is a scenario in which there should be risk management intervention in patient safety: 
[...] in the use of vague expressions. When necessary, use the expression "if necessary" or "SOS", it should define: dose; dosage; maximum daily dose should be clearly described; and condition that determines use or interruption of medicine use. (P9)

In the Violence Prevention subcategory, participants mentioned both physical and sexual violence and suicide attempts. They reported that there is a need to discuss this issue, so that professionals have guidelines to follow when there is this type of occurrence. They also mentioned space for discussion relevance to be in the multidisciplinary team, so that the analysis is made by different visions and areas.

[...] this topic is very important. We have tried to discuss it over and over again, without success. And then, when something happens, there are different behaviors, because it does not have a pattern to follow. (P5)

[...] we need to discuss this among multidisciplinary team, as it is a controversial subject and has to be seen from all angles: from psychology, from nursing, from social service, finally, by all. (P1)

When discussing risk factors, participants report that patients with mental disorders have important characteristics that should be considered when assessing risk:

[...] persecutory delusions, sometimes confuse us with what afflicts them. (P5)

[...] difficulty communicating the patient, who may be aggressive because of this difficulty. (P11)

[...] patient is vulnerable. Another more active patient can push, beat, among other things. (P4)

[...] in the case, a hypersexualization, which can be a great factor for sexual abuse. (P1)

There was intense discussion on measures to prevent violence. In relation to the suicide attempt, several actions that are already carried out in the institution were incorporated into the violence protocol, in order to establish standardization, such as surveillance of unsafe objects entering, supervised bathing, maintenance of protection infrastructure (windows and grids), as well as psychological counseling to identify suicidal attitudes and behaviors.

Participants reported on the importance of involving family members, as well as improving the professional approach and monitoring the risk of aggression: "Guiding the family about the importance of not bringing potentially dangerous belongings.

[...] in fact, have to speak at admission, which can be dangerous. Sometimes they have no notion of danger. (P7)

[...] improving the professional approach. Some do not do it right. (P5)

[...] patients sometimes confuse the employee with someone from his past, I find it interesting to make necessary reshuffling of employees and/or patients between the infirmaries based on the risk of aggression. (P10)

\section{Drafting of diagram and textual proposal of software for internal management of incident reports}

In this category, participants relate the efficiency of the elaborated tools and the ease of using them, concluding that they are functional and adequate to the work process developed in the institution.

The risk management tree diagram in the safety of patients with mental disorders is a management technology that systematically presents steps of risk management in the safety of patients with mental disorders, which are: risk identification, risk analysis, risk assessment and risk management. Each step is deployed in actions that must be performed to achieve patient safety, and each action, in turn, has a control matrix that specifies who, when and if it is completed or not. The textual proposal for software for internal management of incident reports, also characterized as management technology, is a tool that will allow the monitoring of risks and adverse events in the institution.

[...] textual proposal for notification was also well summarized and easy to complete. And the best was that everyone had the opportunity to contribute and give their opinion. (P11)

[...] diagram is a very good tool. It summarizes, in fact, what we are going to do in patient safety. (P6)

[...] the two tools are satisfactory. Easy to understand and all objective. The textual proposal for the notification is clear, and I think the team will adapt. (P5)

\section{DISCUSSION}

Through action research, risk management was implemented in the safety of patients with mental disorders at a reference mental health hospital. Action research has as a characteristic involvement of the researcher with participants and research, being a collective production of knowledge. It is possible for the members of an organization to participate in planning and changing the reality in which they are inserted ${ }^{(11)}$. In fact, this perception of team building was perceived and valued by the group.

Patient Safety is widely discussed and studied, but specifically in mental health, this practice is still incipient ${ }^{(6)}$. It is pointed out that security is articulated as the primary objective of hospital psychiatric care, but this apparently beneficial value is rooted in fear, stigma and a history of institutionalization. Nursing practices aimed at maintaining safety in hospital settings are still ineffective and harmful to patients and nurses, and professionals must share responsibilities with patients and agree on strategies together ${ }^{(12)}$.

The results of this research suggest that mental health is a very specific care and that the patient with mental disorder has many peculiarities due to their psychic state. Some issues pointed out by participants, such as bed change and the attempt to change their name to receive another medication; hygiene of the unit with patients present, absence of lamps in corridors and units; wrong technique of restraint and damage indicated the need to devise strategies to reduce such risks. Furthermore, it is necessary that care given to the patient with mental disorder has, in 
addition to care already applied to the clinical patient regarding their organic condition, attention to the particularities and possible predisposing factors to situations that may be harmful to the patient and/or team that watches him ${ }^{(6)}$.

Faced with these problems, professionals elaborated protocols as a strategy to define standards of care and increase the quality of services. Protocol implementation for organization of care can provide greater satisfaction for the nursing team and for the patient, as well as greater safety in performing the procedures, reducing the risks for professionals and patients ${ }^{(13)}$.

Environment plays a significant role in patient safety as there are a variety of incidents that need to be considered, including suicide and other forms of self-injury, assaults on others, and inadvertent damage caused by falls and other accidents related to facility characteristics ${ }^{(14)}$.

Seeking better patient and employee safety, a mental health organization in Ontario, Canada, has implemented a protocol to prevent unsafe items from entering a psychiatric inpatient unit. After the protocol was implemented, it observed a significant reduction in the entry of unsafe items in the unit, improving the safety of patients, employees and visitors ${ }^{(8))}$. Likewise, violence protocol, developed by the multidisciplinary team, addresses the surveillance of the entry of insecure objects as a way to prevent aggression or suicide attempt, as well as dealing with infrastructure and environmental issues.

In Brazil, minimum protocols have been defined for patient safety, which may be adequate according to the patient profile of the institution ${ }^{(15-16)}$. Thus, based on the characteristics of the profile and the risks to which the patient with mental disorder is exposed, priorities have been defined for risk management, since the actions must result from an adequate knowledge of the reality of the health of the place, from this, to construct an effectively resolute practice ${ }^{(17)}$. The priorities defined by participants demonstrate that situations, beyond those already evidenced by the World Health Organization, such as evasion prevention, restraint injury and violence, are common in mental health services and should be considered and discussed in the context of patient safety.

Thus, risk management in the safety of patients with mental disorders comprises a process of systematization and application of policies, procedures and practices for identification, assessment, treatment, monitoring and critical analysis of risks. Participation of the whole team is necessary, involving from managers to performers of activities, as this ensures that the risk management reaches the local problematic of angles and strategic positions ${ }^{(16)}$.

\section{Study limitations}

The need to divide study participants into two action research groups represented a limitation in the joint discussion of themes in the same space. Despite this limitation, this study was able to reach relevant and innovative discussions about patient safety in mental health, as well as to encourage and strengthen the patient safety culture, beginning the change of practices and concepts in this institution.

\section{Contributions to Nursing and Health}

For the nursing care of patients with mental disorders, the results of this study offer a set of management tools that serve as a basis for a qualified care organization, assuring to the professional a standardization of the actions based on patient safety principles.

\section{FINAL CONSIDERATIONS}

This study allowed risk management implementation in patient safety in a reference hospital in mental health; and this process was possible through the action research strategy. Although the topic of patient safety is widely discussed worldwide, its discussion in the mental health setting is still restricted. Action research enabled a collective and participative construction of tools for risk management in the safety of patients with mental disorders.

This research built three management tools: 1) Risk management tree diagram in the safety of patients with mental disorders, management technology that systematically presents risk management in the safety of patients with mental disorders, which are: risk identification, risk analysis, risk assessment and risk management. Each step is deployed in actions that must be performed to reach patient safety and, in turn, each action has a control matrix that specifies who, when and if it is completed or not; 2) Safety Protocols for Patients with Mental Disorder, management technology consisting of seven protocols, which are: Patient Correct Identification, Hand Hygiene, Violence Prevention, Prescription and Safe Administration of Medications, Patient Evasion Prevention, Preventing Restraint Injury, and Fall Prevention; 3) textual proposal of software for internal management of incident notifications, a management technology that constitutes a form for notification of incidents that can generate harm to the patient.

Finally, this study reaffirms the need for new studies on mental health and safe care, mainly using strategies that involve the whole team in the development of practices and in the effective management of risks to the safety of patients with mental disorders.

\section{REFERENCES}

1. Fermo VC, Radünz V, Rosa LM, Marinho MM. Professional attitudes toward patient safety culture in a bone marrow transplant unit. Rev Gaúcha Enferm. 2016;37(1):e55716. doi: 10.1590/1983-1447.2016.01.55716

2. Agência Nacional de Vigilância Sanitária (ANVISA). Resolução da Diretoria Colegiada - RDC n 63 , de 25 de novembro de 2011 . Dispõe sobre os requisitos de boas práticas de funcionamento para os serviços de saúde [Internet]. Brasília: ANVISA; 2011 [cited 2014 Dec 02 ]. Available from: https://www20.anvisa.gov.br/segurancadopaciente/index.php/legislacao/item/rdc-63-de-25-de-novembro-de-2011

3. Agência Nacional de Vigilância Sanitária (ANVISA). Portaria n 529, de $1^{\circ}$ de abril de 2013. Institui o Programa Nacional de Segurança do 
Paciente (PNSP) [Internet]. Brasília: ANVISA; 2013 [cited 2014 Dec 02]. Available from: http://bvsms.saude.gov.br/bvs/saudelegis/gm/2013/ prt0529_01_04_2013.html

4. Agência Nacional de Vigilância Sanitária (ANVISA). Resolução da Diretoria Colegiada - RDC n 36, de 25 de julho de 2013. Institui ações para a segurança do paciente em serviços de saúde e dá outras providências [Internet]. Brasília: ANVISA; 2013 [cited 2014 Dec 02]. Available from: http://bvsms.saude.gov.br/bvs/saudelegis/anvisa/2013/rdc0036_25_07_2013.html

5. Fernandes LGG, Tourinho FSV, Souza NL, Menezes RMP. Contribution of James Reason to patient safety: reflection for nursing practice. Rev Enferm UFPE. 2014;8(Suppl 1):2507-12. doi: 10.5205/reuol.5927-50900-1-SM.0807suppl201440

6. Briner M, Manser T. Clinical risk management in mental health: a qualitative study of main risks and related organizational management practices. BMC Health Serv Res. 2013;13:44. doi: 10.1186/1472-6963-13-44

7. Staggs VS. Deviations in monthly staffing and injurious assaults against staff and patients on psychiatric units. Res Nurs Health. 2016;39(5):347-52 10.1002/nur.21735

8. Abela-Dimech F, Johnston K, Strudwick G. Development and pilot implementation of a search protocol to improve patient safety on a psychiatric inpatient unit. Clin Nurse Spec. 2017;31(2):104-14. doi: 10.1097/NUR.0000000000000281

9. Thiollent M. Metodologia da Pesquisa-ação. 18a ed. São Paulo: Cortez; 2011.

10. Oliveira DC. Análise de conteúdo temático-categorial: uma proposta de sistematização. Rev Enferm UERJ [Internet]. 2008 [cited 2015 Jun 15];16(4):569-76. Available from: www.facenf.uerj.br/v16n4/v16n4a19.pdf

11. Carvalho e Silva J, Morais ER, Figueiredo MLF, Tyrrell MAR. Pesquisa-ação: concepções e aplicabilidade nos estudos em enfermagem. Rev Bras Enferm. 2011;64(3):592-5. doi: 10.1590/S0034-71672011000300026

12. Slemon A, Jenkins E, Bungay V. Safety in psychiatric inpatient care: The impact of risk management culture on mental health nursing practice. Nurs Inq. 2017;24:e12199. doi: 10.1111/nin.12199

13. Miranda AL, Oliveira ALL, Nacer DT, Aguiar CAM. Results after implementation of a protocol on the incidence of urinary tract infection in an intensive care unit. Rev Latino-Am Enfermagem. 2016;24:e2804. doi: 10.1590/1518-8345.0866.2804

14. Bayramzadeh S. An Assessment of Levels of Safety in Psychiatric Units. HERD. 2017;10(2):66-80. doi: 10.1177/1937586716656002

15. Ministério da Saúde (BR). Portaria n².095, de 24 de setembro de 2013. Aprova os protocolos básicos de segurança do paciente [Internet]. Brasília: Ministério da Saúde; 2013 [cited 2014 Dec 02]. Available from: http://bvsms.saude.gov.br/bvs/saudelegis/gm/2013/ prt2095_24_09_2013.html

16. Ministério da Saúde (BR). Portaria $n^{\circ}$ 1.377, de 9 de julho de 2013. Aprova os protocolos de segurança do paciente [Internet]. Brasília: Ministério da Saúde; 2013 [cited 2014 Dec 02]. Available from: http://bvsms.saude.gov.br/bvs/saudelegis/gm/2013/prt1377_09_07_2013.html

17. Aosani TR, Nunes KG. A saúde mental na atenção básica: a percepção dos profissionais de saúde. Rev Psicol Saúde [Internet]. 2013 [cited 2017 Jun 15];5(2):71-80. Available from: http://pepsic.bvsalud.org/scielo.php?script=sci_arttext\&pid=S2177-093X2013000200002\&lng=pt\& $\mathrm{nrm}=\mathrm{iso} \& \mathrm{tlng}=\mathrm{pt}$ 